\title{
Coating Characterizations and Evaluation of Ceramic-Metal Mixture Slurry Based Thermal Barrier Coating for Automotive Turbocharger Turbine Application
}

\author{
Alias Mohd Noor*, Fadzlun Nadrah Sharuddin, Uday M. Basheer
}

\begin{abstract}
Turbocharging the internal combustion engine (ICE) is to increase the power density of the engine or known as the downsizing of the engine. Large amount of heat energy is wasted through the exhaust manifold, coolant, convective and radiate heat transfer. The amount of heat loss generated to the surrounding by operating turbine volute will affect the service life of some automotive components. The current material tungsten used for heavy duty automotive turbine volute casing is heavier and costly if to compare to a new suggested material nickel with thermal barrier ceramic coating as an alternative. Thermal barrier coating is an alternative method for insulating cheaper and lighter engineering components operating in extreme temperature condition, there exist different coating techniques, but high installation cost and high technical skills requirement have restricted their widespread acceptance. The need of simple and cost effective thermal barrier coating has become necessary for the alternative coating method. In this study, slurry based coating method was adopted and the $\mathrm{Ni} /$ Basalt slurry mixture was coated by using an automatic film applicator in order ensures a uniform thickness of the coating. Appropriate amount of nickel powder and basalt fibre were mixed to produce the slurry mixture. A composition of $70 \mathrm{wt} \%$ nickel powder and $30 \mathrm{wt} \%$ basalt fibre was used in depositing the thermal barrier coating layer on nickel substrate. The coating microstructures were analyzed and evaluated by using Optical Microscopy (OM) and Scanning Electron Microscopy (SEM). The coatings were also examined with EDX line (Energy Dispersive X-ray Spectroscopy) in order to determine the phases formed during the coating process. The mechanical properties including adhesion strength and Vickers micro hardness were measured. The results shown that the Ni/Basalt slurry based coating was suitable and appropriate for the coating process of the substrate as an application in the inner passage of the casing.
\end{abstract}

Keywords - Ceramic materials, thermal barrier coating, turbocharger turbine, automotive engine

Alias Mohd Noor* (corresponding author)

Universiti Teknologi Malaysia

Malaysia

Fadzlun Nadrah Sharuddin

Universiti Teknologi Malaysia

Uday M. Basheer

Universiti Teknologi Malaysia

\section{Introduction}

In recent years, improving the performances of automotive internal combustion (IC) engines has been widely investigated by many researchers. Typically, an (IC) engine produces high amount of waste heat. In IC engines, about $70 \%$ of thermal energy is released through the exhaust, coolant and to the ambient air (Sharma, 2015). The wasted exhaust gas released to the environment is polluting the air and increases the greenhouse effect. The huge amount of heat energy rejected can be recovered up to $40 \%$ depending on the engine load (Sharma, 2015; Saidur et al., 2012). This recovery of waste heat energy can be achieved by adopting turbocharging technology.

Turbocharger is light-weight, compact, portable and highly durable (Romagnoli and Martinez-Botas, 2012; Sharma, 2015). Commonly, a turbocharger is consist of several major component such as turbine, compressor, shaft that connects turbine and compressor, valve and housing (Saidur et al., 2012). The waste heat extracted from the IC engine will expand in the turbine then, driving the compressor to compress ambient air into the combustion chamber. This process of heat recovery will boost the intake air which in turns improve the power density of the engine (Yang et al., 2015). It is the key enabler to a highly downsized engine technology for spark ignition and compressor ignition engine as it increases the specific power output and reducing the cylinder volume and weight of the IC engine (Sharma, 2015; Galindo et al., 2013; Saidur et al., 2012). Turbocharger is widely used in automotive IC engine not only to recover exhaust energy, but also to reduce pollutant emissions and improve fuel economy. It is wellestablished for all automotive engine sector such as diesel and gasoline engines (Galindo et al., 2013; Bontempo et al., 2015). This is proven by the decreasing of fuel consumption in both sectors. Turbocharged diesel and gasoline engine have improved the fuel economy up to $30-50 \%$ and $5-20 \%$ respectively (Saidur et al., 2012). One of the major factor is the weights of the turbine and compressor. Besides, turbochargers are also at high risk for hot corrosion attack. These disadvantages can be improved by introducing new lighter materials and adopting thermal barrier coating (TBC) technology for better heat and corrosion resistance.

TBCs are widely used to extend the life and enhance the durability of components working in a severe environment. It gives thermal, oxidation and wear protection to the high temperature components of turbochargers (Gosai and Nagarsheth, 2014). Basically, TBC is a multi-layered coating system comprises of few materials having high 
insulating properties deposited on top of a metal substrate (Gosai and Nagarsheth, 2014; Kumar and Balasubramanian, 2016; Nor et al., 2014). The multi-layered materials will reduced the surface temperature of the metallic substrate hence, protect the components and keep the temperature cooler than the exhaust gas entering the turbocharger. Kumar and Balasubramanian (2016) stated that application of $\mathrm{TBCs}$ can reduced surface temperature of a metal component up to $300^{\circ} \mathrm{C}$. These high insulating layers enable the working temperature to be increased without affecting the metal substrate (Josell et al., 2015). In short, TBCs allows the turbocharger to operate above the melting temperature of the super alloy, thereby increasing the thermal efficiencies of the turbocharged IC engine. In addition, TBCs also offer benefits including increased in fuel efficiency, thrust to weight ratio and lower amount of heat lost to cooling water and ambient air (Hejwowski, 2010; Kumar and Balasubramanian, 2016). Nowadays, TBCs have been successfully adopted in automotive engine metal components such as turbine blades, nozzle, valve, cylinder lining and piston crown.

\section{Thermal Barrier Coating (TBC) for Turbocharger Turbine}

\section{A. Ceramic Application as TBC on Turbocharger Turbine}

In turbocharger system, the most crucial component of is the turbine. Turbocharger turbine is important as it recovers the exhaust gases from the combustion chamber and convert it to kinetic energy for charging (Laengler et al., 2011; Yang et al., 2015). For decades, ceramic materials have been an excellent Thermal Barrier Coating (TBC) in automotive industry. Ceramic is a low density material which possesses excellent thermal properties, good oxidation and wear resistance (Nor et al., 2014). These are the main factors that made ceramic coatings acknowledgeable in automotive industry. Therefore, this study is focusing on finding the suitable metal and ceramic materials that can reduce the weight, heat loss and cost of the turbocharger casing.

\section{B. Heat Transfer Analysis in Turbocharger Turbine}

Generally, work transfer such as friction and mechanical fatigue are affecting the performance and life of a turbocharger more than heat transfer (Burke et al., 2015). But, even though the effect is small, the analysis is still crucial which most of current practices neglected. When it comes to turbine analysis, heat transfer effect is as much important as other contributing factors of turbocharger performances. Burke et al. (2015) stated that neglecting heat transfer in analysis of turbocharger turbine will leads to less accurate prediction of inter-cooling gas temperatures. According to Burke's study, 20 percent and more of enthalpy drop in the turbine are represents by heat transfer. That amount of heat then lost to the environment, oil and cooling water.
As turbocharger turbine receives the highest heat from the exhaust gas, study on the heat losses becomes crucial. There are few researches conducted on the heat flow in the turbine (Olmeda et al., 2013; Payri et al., 2014; Serrano et al., 2015). Olmeda et al. (2013) developed a method of calculating heat fluxes in turbocharger of passenger car to determine the heat flows. One dimensional lumped model was used to solve the heat transfer. Payri et al. (2014) is also investigating the heat fluxes effect on external the heat losses of a turbocharger. The developed external heat transfer model was considering all source of heat from external surfaces of turbocharger such as convection and radiation. The results showed that the highest heat fluxes come from turbine surface due to its high temperature and big areas. Recently, heat transfer including the mechanical losses study was conducted by Serrano et al. (2015). The heat transfers and mechanical losses were studied by using one dimensional simulation codes coupled with engine model.

Apart from turbocharger turbine, the casing itself plays an important role in controlling the heat flows from the exhaust to the shaft and compressor. Burke et al. (2015) studied on the heat transfer in the turbine at transient state showed that thermal inertia of the casing gives big impact on the heat flows due to temperature difference between the exhaust gas and the turbine wall. Furthermore, a study also stated that high surface temperature of the turbine casing losses 26 percent of total power output through convection and radiation (Verstraete, 2013). These shows that further study on heat transfer need to be done on the volute casing in order to reduce the heat lost and increase the turbocharger overall performance. Figure 1 shows the image of a turbocharger turbine volute casing.

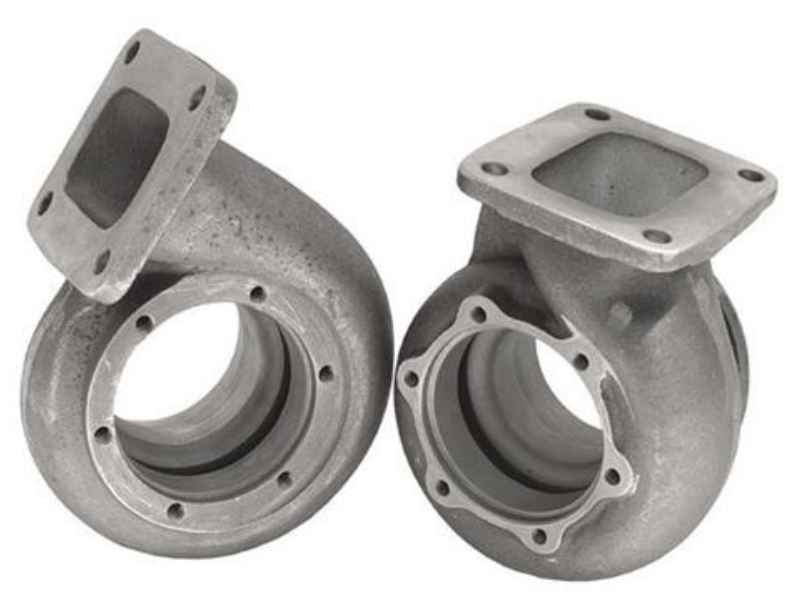

Figure 1 - Image of turbocharger turbine volute casing

\section{Ceramics as Thermal Barrier Coating}

Ceramics are commonly used as thermal barrier coating in automotive IC engines. Ceramic coatings protect the substrate which is the metal component by preventing thermal fatigue and shocks (Sivakumar and Senthil Kumar, 2014). The capabilities of ceramic coatings not only as heat resisting medium, but also helps in reducing the emission of 
polluted gases such as hydrocarbon and carbon monoxide as being claimed by Sivakumar and Senthil Kumar in their study. Ceramic materials that are commonly used in automotive engines are silicon nitride, silicon carbide and yttria-stabilized zirconia.

\section{A. Silicon Nitride}

Table 1 shows some of the common properties of silicon nitride $\left(\mathrm{Si}_{3} \mathrm{~N}_{4}\right) . \mathrm{Si}_{3} \mathrm{~N}_{4}$ is widely used in many areas such as structural and automotive industries. It is a type of ceramic material that possessed good mechanical, thermal and chemical properties (Heimann, 2010). With a melting temperature of $1900^{\circ} \mathrm{C}, \mathrm{Si}_{3} \mathrm{~N}_{4}$ ceramic is typically attractive to be used in elevated temperature applications. Some remarkable properties of $\mathrm{Si}_{3} \mathrm{~N}_{4}$ ceramic include good oxidation and abrasion resistance, high hardness and toughness, low friction and wear resistance (BocanegraBernal and Matovic, 2010; Chauhan and Rawal, 2014; Myagkov et al., 2014). Besides, having low density makes this ceramic material a great prospect for coating application in turbocharger. On the other hand, gas turbine components made up from $\mathrm{Si}_{3} \mathrm{~N}_{4}$ are greatly produced by engine manufacturers as the results for mechanical response of the material to static, dynamic and cyclic conditions at high temperature is reliable (Bocanegra-Bernal and Matovic, 2010). Currently, many automotive engine components subjected to severe working temperature are coated with $\mathrm{Si}_{3} \mathrm{~N}_{4}$ ceramic. For example, heat exchangers, exhaust valves, bearings, stationary blades, nozzle and also turbocharger rotors (Bocanegra-Bernal and Matovic, 2010; Heimann, 2010). Other than automotive parts, $\mathrm{Si}_{3} \mathrm{~N}_{4}$ ceramic has also showed an improvement of cutting tools for high speed machining of super alloys (Heimann, 2010; Chauhan and Rawal 2014).

TABLE 1 - PROPERTIES OF SILICON NITRIDE

\begin{tabular}{|c|l|l|}
\hline \multicolumn{1}{|c|}{ PROPERTIES } & VALUE & UNITS \\
\hline PHYSICAL & & \\
\hline Melting point & 1900 & ${ }^{\circ} \mathrm{C}$ \\
\hline Density & 3.31 & $\mathrm{~g} / \mathrm{cm}^{3}$ \\
\hline Hardness & 2200 & $\mathrm{~kg} / \mathrm{mm}^{2}$ \\
\hline MECHANICAL & & $\mathrm{MPa}$ \\
\hline Compressive Strength & $689-2790$ & $\mathrm{MPa}$ \\
\hline Tensile Strength & $360-434$ & $\mathrm{GPa}$ \\
\hline Modulus of Elasticity & 317 & $\mathrm{MPa}$ \\
\hline Flexural Strength & $679-896$ & $\mathrm{MPa} \mathrm{x} \mathrm{m}{ }^{\mathrm{I} / 2}$ \\
\hline Fracture Toughness & $5-8$ & $\mathrm{~W} / \mathrm{m}-\mathrm{K}$ \\
\hline THERMAL & & $\mu \mathrm{m} / \mathrm{m}-{ }^{\circ} \mathrm{C}$ \\
\hline Thermal Conductivity & 27 & $\mathrm{cal} / \mathrm{g}-{ }^{\circ} \mathrm{C}$ \\
\hline $\begin{array}{l}\text { Thermal Expansion } \\
\text { Coefficient }\end{array}$ & 3.4 & \\
\hline \begin{tabular}{l} 
Specific Heat \\
\hline
\end{tabular} & 0.17 & \\
\hline
\end{tabular}

Although Si3N4 ceramic has shown a great success in coating automotive parts, there are still some challenges and limitations of the ceramic material. It is widely known that Si3N4 ceramic can hold a high temperature and shows excellent strength. But, when the operating temperature exceeds $1000^{\circ} \mathrm{C}$, the ceramic is vulnerable to oxidation (Sommers et al., 2010). Basically, a pure Si3N4 ceramic exists as a covalent compound. Therefore, its bulk diffusion is too low to be consolidated. As the solution, the pure Si3N4 ceramic is sintered with nitride additives (BocanegraBernal and Matovic, 2010). Unfortunately, these additives worsen the strength of the ceramic at high temperature for which the additives remain as grain boundary glassy phase. Further, coating the Si3N4 ceramic also undergoes some challenges. Heimann (2010) claims that by using thermal spray technologies to deposit a thick Si3N4 ceramic coating, the material dissociates above $1800^{\circ} \mathrm{C}$. Thermal spray method also showed a limited achievement in coating Si3N4 ceramic using metallic or silicate glass binders since the amount of Silicon Nitride in the coating is less and having large amount of unwanted phases which increase the brittleness of the coating. In addition, this ceramic material has low crack resistance plus low level of destruction viscosity. The process of coating and machining Si3N4 ceramic automotive parts is also complex and costly (Myagkov et al., 2014).

\section{B. Silicon Carbide}

Table 2 shows some of the common properties of silicon carbide ( $\mathrm{SiC})$. An extremely high melting temperature of $\mathrm{SiC}$ increased its reliability in application of elevated structural and automotive components. SiC ceramic exhibits loads of excellent properties such as high strength, high hardness, high wear and corrosion resistance, and chemically stable (Matovi et al., 2013; Zhang et al., 2013; Kumar et al., 2012; Mukherjee et al., 2014; Park et al., 2014). This ceramic material possessed all the refractory criteria. SiC ceramic does not oxidize up to $1700{ }^{\circ} \mathrm{C}$ due to the formation of silica glass layer which restrain the diffusion of oxygen to the metal substrate (Matovi et al., 2013). Excellent thermal shock resistance is also one of the attractive properties of $\mathrm{SiC}$ ceramic since it exhibits high thermal conductivity and low thermal expansion coefficient (Kumar et al., 2012). The high temperature stability and thermal shock resistance makes this ceramic material suit well as TBC in gas turbine of automotive IC engines. For example, heat exchangers, turbine blades and also turbocharger rotors are coated with $\mathrm{SiC}$ ceramic to increase their performance in elevated temperature. (Zhang et al., 2014; Zhang et al., 2015). In addition, the low density of $\mathrm{SiC}$ ceramic also contributed in higher performance of rockets and satellites propulsion systems.

TABLE 2 - PROPERTIES OF SILICON CARBIDE

\begin{tabular}{|l|l|l|}
\hline PROPERTIES & VALUE & UNITS \\
\hline PHYSICAL & & \\
\hline Melting point & 2730 & ${ }^{\circ} \mathrm{C}$ \\
\hline Density & 3.21 & $\mathrm{~g} / \mathrm{cm}^{3}$ \\
\hline
\end{tabular}




\begin{tabular}{|l|l|l|}
\hline Hardness & 2800 & $\mathrm{~kg} / \mathrm{mm}^{2}$ \\
\hline MECHANICAL & & \\
\hline Compressive Strength & $1725-2500$ & $\mathrm{MPa}$ \\
\hline Tensile Strength & 310 & $\mathrm{Mpa}$ \\
\hline Modulus of Elasticity & 476 & $\mathrm{Gpa}$ \\
\hline Flexural Strength & 324 & $\mathrm{Mpa}$ \\
\hline Fracture Toughness & 4.0 & $\mathrm{Mpa} \times \mathrm{m}^{1 / 2}$ \\
\hline THERMAL & & $\mathrm{W} / \mathrm{m}-\mathrm{K}$ \\
\hline Thermal Conductivity & 41 & $\mu \mathrm{m} / \mathrm{m}^{-}{ }^{\circ} \mathrm{C}$ \\
\hline $\begin{array}{l}\text { Thermal Expansion } \\
\text { Coefficient }\end{array}$ & 5.12 & $\mathrm{cal} / \mathrm{g}-{ }^{\circ} \mathrm{C}$ \\
\hline Specific Heat & 0.15 & \\
\hline
\end{tabular}

and thermal properties of Yttria Stabilized Zirconia (YSZ) is way better since it has a good combination of the low thermal conductivity and phase stability. YSZ is labelled as the state-of-art for TBC materials (Di Girolamo et al., 2015; Jalaludin et al., 2013). This ceramic material has shown a great performance in many areas such as turbocharger turbine coating, chemical sensors, optical coatings etc. The focus area of YSZ ceramic coating is in automotive IC engines. Sivakumar and Senthil Kumar (2014) studied on the YZS coating on piston crown. Figure 2 depicted the uncoated and YSZ coated piston.

TABLE 3 - PROPERTIES OF ZIRCONIA

It is widely known that $\mathrm{SiC}$ ceramic material is made up of covalent compound. Due to its high covalent energy and low self-diffusion coefficients, $\mathrm{SiC}$ ceramic is difficult to sinter (Kumar et al., 2012). Liquid phase sintering with oxides as the sintering additives is developed to improve the microstructure of SiC. Zhang et al. (2013) discussed that the common oxides used in the sintering process which are Aluminium Oxide $\left(\mathrm{Al}_{2} \mathrm{O}_{3}\right)$ and Ytria Oxide $\left(\mathrm{Y}_{2} \mathrm{O}_{3}\right)$, does produced fined and homogeneous microstructure. But the challenges arises when it comes to fabrication of parts with big size and complex shape. Due to high hardness of SiC, post machining will be difficult and costly where diamond tools ultrasonic machining technique are required thus, decreasing the productivities (Kumar et al., 2012; Zhang et al., 2015). The commonly used method for deposition of SiC ceramic coating is chemical vapour deposition (CVD). Even though CVD is widely used, micro cracks in the coating are still un-avoidable. Higher rate of oxygen diffusion in the coating which causes by mismatch of thermal expansion coefficient between the metal and coating is one of the reasons. Although the micro cracks usually healed above the deposition temperature of CVD due to the production of silica, oxygen can still diffused through the micro cracks below the deposition temperature that leads to oxidation in the carbon phase (Wu et al., 2015). Other solution for the micro cracks in $\mathrm{SiC}$ ceramic coating is by adopting glasssealing method during oxidation. Adequate viscosity of the formation of borosilicate glass will sealed the cracks. But, this solution method also turned out a failure as the borosilicate glass evaporates above $450^{\circ} \mathrm{C}$. Thereby, oxidation resistance of $\mathrm{SiC}$-based coatings in higher temperature ranging from $700^{\circ} \mathrm{C}$ to $1100^{\circ} \mathrm{C}$ is still a worrisome.

\section{Yttria Stabilized Zirconia}

Table 3 shows some of the common properties of Zirconia $\left(\mathrm{ZrO}_{2}\right)$. As shown in the table, Zirconia has the lowest thermal conductivity value compared to $\mathrm{SiC}$ and $\mathrm{Si}_{3} \mathrm{~N}_{4}$ ceramics. It makes $\mathrm{ZrO}_{2}$ ceramic the best candidate for thermal insulation materials. Application of $\mathrm{ZrO}_{2}$ ceramic in TBC is well established for its many excellent properties such as ultimately low thermal conductivity, high thermal shock resistance, extremely high melting point, and good wear and corrosion resistance at high temperature (Gosai and Nagarsheth, 2014; Keshavarz et al., 2013; Ahmadipidani et al., 2014). In order to maximize its performance as TBC, $\mathrm{ZrO}_{2}$ usually doped with oxides. $\mathrm{Y}_{2} \mathrm{O}_{3}$ is the most commonly used oxides to stabilize $\mathrm{ZrO}_{2}$. The mechanical

\begin{tabular}{|c|c|c|}
\hline PROPERTIES & VALUE & UNITS \\
\hline PHYSICAL & & \\
\hline Melting point & 1855 & ${ }^{\circ} \mathrm{C}$ \\
\hline Density & 6.04 & $\mathrm{~g} / \mathrm{cm}^{3}$ \\
\hline Hardness & 1600 & $\mathrm{~kg} / \mathrm{mm}^{2}$ \\
\hline MECHANICAL & & \\
\hline Compressive Strength & 2500 & $\mathrm{MPa}$ \\
\hline Tensile Strength & 248 & $\mathrm{MPa}$ \\
\hline Modulus of Elasticity & 207 & $\mathrm{GPa}$ \\
\hline Flexural Strength & 900 & $\mathrm{MPa}$ \\
\hline Fracture Toughness & 13 & $\mathrm{MPa} \times \mathrm{m}^{1 / 2}$ \\
\hline THERMAL & & \\
\hline Thermal Conductivity & 2.7 & $\mathrm{~W} / \mathrm{m}-\mathrm{K}$ \\
\hline $\begin{array}{c}\text { Thermal Expansion } \\
\text { Coefficient }\end{array}$ & 11.0 & $\mu \mathrm{m} / \mathrm{m}-{ }^{\circ} \mathrm{C}$ \\
\hline Specific Heat & 0.10 & $\mathrm{cal} / \mathrm{g}-{ }^{\circ} \mathrm{C}$ \\
\hline
\end{tabular}
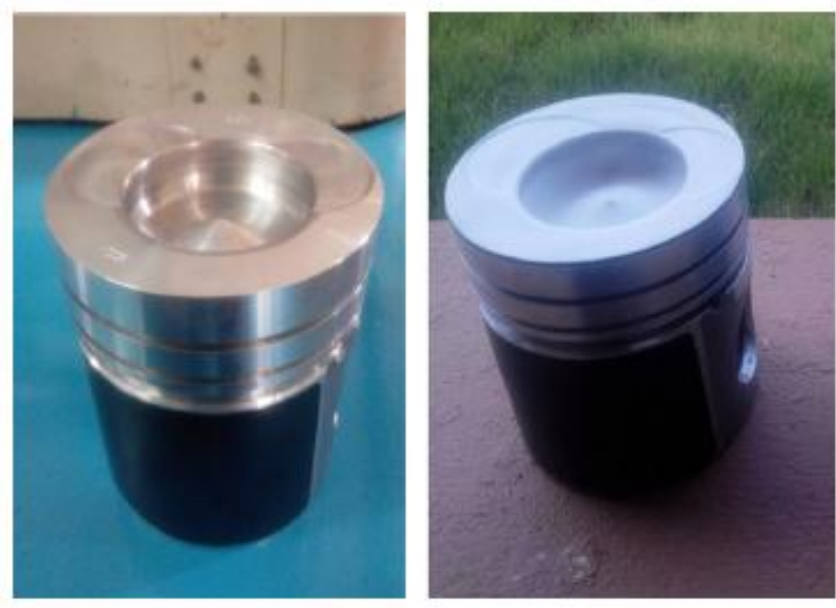

Figure 2 - Snapshots of uncoated baseline engine piston (left) and YSZ coated piston (right). (Sivakumar and Senthil Kumar 2014).

It is found that the brake specific fuel consumption and brake thermal efficiency of the YSZ coated IC engine has been improved by $25 \%$ and $34 \%$ respectively. As the hotter walls and residual gas decrease the density of the inducted air, an increased in volumetric efficiency is also observed in the YSZ coated engine. On top of that, the emissions of Carbon Monoxide (CO) and Hydrocarbon (HC) are also reduced by $2.7 \%$ and $35.27 \%$ respectively. The excellent performance of YSZ ceramic coating in combustion chamber components are also proven by Gosai and Nagarsheth (2014). YSZ coatings are deposited on piston 
crown, cylinder head and liners of a multi cylinder vertical water cooled self-governed diesel engine.

\section{Basalt Fibre}

Theoretically, basalt is a very hot fluid material under the crust of the earth which becomes solid in the open air. The solidified material is also named as basalt rocks, come from volcanic magma and flood volcanoes (Singha, 2012). Basalt fiber is then produced by extrusion and melting process of basalt rocks. These processes are simpler and energy efficient compared to other type of fibers (Lu et al., 2015; Dhand et al., 2014). Extrusion process will finely divide the Basalt rocks into small particles to form fibers. Basalt fibers consists of minerals plagioclase, pyroxene, and olivine (Singha, 2012). Moreover, basalt fibers is an inorganic fibre which has many interesting properties such as high strength, high chemical stability, high corrosion resistance, high elasticity modulus, excellent heat resistance, and also good resistance to weather, alkaline and acids (Singha, 2012; Dhand et al., 2014; Fiore et al, 2015). Furthermore, basalt fiber is a natural material which is ecofriendly, non-toxic, easy to handle and most importantly, it is inexpensive. Besides, basalt fiber are stable at very low temperatures (about $200^{\circ} \mathrm{C}$ ) up to $900^{\circ} \mathrm{C}$ (Fiore et al, 2015).

Table 4 shows some of the thermal properties of the basalt fibre. It is clear that basalt fibre has better thermal properties compared to glass fibre and can stably resist heat at high operating temperatures. On top of that, basalt fibre is also known to have higher failure strain compared to carbon fibre and it is also lighter than metal (Singha, 2012; Lu et al., 2015). In addition, the low cost of this fiber is one of the most interesting aspects. According to $\mathrm{Lu}$ (2015), basalt fibre is cost effective as it does not require any additives in the production process. Singha (2012) states that basalt fibre is much cheaper than carbon fiber. The good qualities and economic friendly makes basalt fibre more preferable compared to other glass fibre. Basalt fibre is increasingly used in automotive and construction industry. Car headliners, brake disc, and clutch are few examples of the applications of basalt fibre. Recyclability is also one of the main factors for its high interest in automobile applications. Other than that, due to its high shock resistance, durable frictional contact with metal and high wear resistance, elevated working temperature, and three times longer service life, reliability of basalt fibre application in automotive industry increased rapidly (Fiore et al, 2015).

TABLE 4 - COMPARISON OF THERMAL PROPERTIES OF BASALT AND GLASS FIBRE

\begin{tabular}{|c|c|c|}
\hline Thermal Properties & Basalt fibre & Glass fibre \\
\hline $\begin{array}{l}\text { Melting temperature } \\
\left({ }^{\circ} \mathrm{C}\right)\end{array}$ & 1280 & 1120 \\
\hline $\begin{array}{l}\text { Maximum operating } \\
\text { temperature }\left({ }^{\circ} \mathrm{C}\right)\end{array}$ & 700 & 480 \\
\hline $\begin{array}{l}\text { Minimum operating } \\
\text { temperature }\left({ }^{\circ} \mathrm{C}\right)\end{array}$ & -2.60 & -60 \\
\hline $\begin{array}{l}\text { Thermal conductivity } \\
(\mathrm{W} / \mathrm{mK})\end{array}$ & $0.031-0.038$ & $0.034-0.04$ \\
\hline $\begin{array}{l}\text { Thermal expansion } \\
\text { coefficient }\end{array}$ & 8.0 & 5.4 \\
\hline
\end{tabular}

\section{$\left(10^{-6} /{ }^{\circ} \mathrm{C}\right)$}

On the other hand, research on properties development of basalt fibre had shown quite an interesting result. For example, Lipatov (2014) studied on the crystallization of 0-7 wt $\%$ of zirconia doped basalt fibre. It was found that the Arrhenius parameter of alumina silicate crystallization is increased as 1-3 wt\% of $\mathrm{ZrO}_{2}$ is doped with basalt fibre. Then, when the $\mathrm{ZrO}_{2}$ content is increased to $7 \mathrm{wt} \%$, the crystallization is changed and the fiber thermal stability is increased significantly. Other researcher has conducted investigations on the thermal properties of basalt short fibre metal matrix composites (MMCs) (Vannan et al., 2014). The coefficient of thermal expansion (CTE) of the composite material reinforced with basalt fibre was studied. The outcome of the study showed an increase of CTE of basalt fibre reinforced MMC when temperature is increased significantly but, a decrease of CTE is observed as the basalt fibre reinforcement is increased. This phenomenon is due to the grain modification of matrix alloy, high reinforcement stiffness and disassociation density of the composites based on the CTE difference between the MMC and fibre. As an advantage, the values of CTE remained constant over a greater range of temperature. Based on all the excellent properties and development of basalt fibre, this fibre is considered as a very promising material and superior to any available fibre to be reinforced with ceramics for many automotive applications. Furthermore, costs in manufacturing and production in industrial applications may be reduced greatly if research on the advantages of Basalt fibre is developed and improved.

\section{Iv. Metal Substrates for Ceramic Coating}

Selecting suitable metal substrate to be coated with TBC is important in order to ensure compatibility with selected ceramic coating. Characteristics of the substrate have to be studied thoroughly because it contributes to the lifetime of the TBC system. The main factor that needs to be taken into account when selecting a suitable substrate is the thermal expansion coefficient matching between the metal and ceramic materials (Eriksson et al., 2013). Large mismatch of thermal expansion coefficient will lead to spallation and failure of TBC system. Nickel alloy is a promising candidate for ceramic coating substrate where the low cost, high oxidation resistance and good mechanical properties attracts many attentions in automotive industry (Yang et al., 2012). These are some of the mainly used substrates in TBC system. By considering all the physical, mechanical and thermal properties especially the thermal expansion coefficient, a suitable substrate can be selected compatible with the ceramic material for TBC.

\section{v. Ceramic Coating Fabrication Techniques}

There are many techniques that can be used to deposit ceramic coating. The most commonly used techniques are air plasma spray (APS) and electron beam physical-vapor deposition (EB-PVD) (Keshavarz et al., 2013; Gao et al., 
2015; Pakseresht et al., 2016). These techniques have shown improvement on the life of turbines and engines performance. Few researchers applied EB-PVD technique in their study and came out with good results (Keshavarz et al., 2013; Mukherjee et al., 2014). Keshavarz et al. (2013) used EB-PVD to deposit YSZ ceramic onto aluminium substrate and reported a significant increase in thermal cyclic life of the component. Mukherjee et al. (2014) also adopted EBPVD technique in their study to deposit SiC ceramic coating as it is a low temperature technique suitable for the ceramic coating. EB-PVD coating technique gives good thermal resistance behavior and stress/strain tolerance to the coating system as it exhibits columnar microstructure. However, this technique deposited the coatings at a low rate which is suitable only for thin film production (Gao et al., 2015). To deposit a thick film is difficult by using EB-PVD method, plus its high cost and higher power requirement limit its application (Kim et al., 2014). Therefore, APS attracts more attention for thick film production. APS technique has been widely used for its flexibility and high deposition rate (Xu et al., 2015; Jin and Zhao, 2015). Many ceramics application nowadays adopted APS technique to due to its ability to coat large component structures. Moreover, APS TBCs were reported to be high in thermal and corrosion resistance (Sobhanverdi and Akbari, 2015; Pakseresht et al., 2016). Even though these two techniques contribute to many excellent improvement, the cost for their applications are high due to the high technology. Thus, a requirement for a simple and low cost ceramic coating technique leads to the use of Automatic Film Applicator. Automatic film application is indeed a simple, cost effective yet a high performance technique of coating which can maintain a constant speed and coat a uniform thickness of film on the substrate (Sheen, 2006). Commonly, hand held coating applicators had difficulties in sustaining speed, distance and thickness of the coating. By using this applicator, the limitations can be overcome and improved.

\section{vI. Methodology}

The flowchart of the whole processes of this study in order to determine the heat transfer of the turbocharger turbine volute casing coated with ceramic is shown in Figure 3.

\section{A. Preparation of Substrate}

The preparation of substrate consists of cutting, sand blasting and surface roughness measurement. Next, the substrate will be sand blasted to get a rough surface. Previous studies reported that sand blasting metal substrates lead to decreasing in oxidation rate plus, increasing in adhesive strength and thermal cycling of the TBC system (Chen et al. 2013; Xu et al. 2014; Khan et al. 2016). After that, surface roughness test will be conducted to know the roughness value of the substrate. Figure 4 and 5 depicted the sand blasting machine and the surface roughness instrument that will be used, respectively.

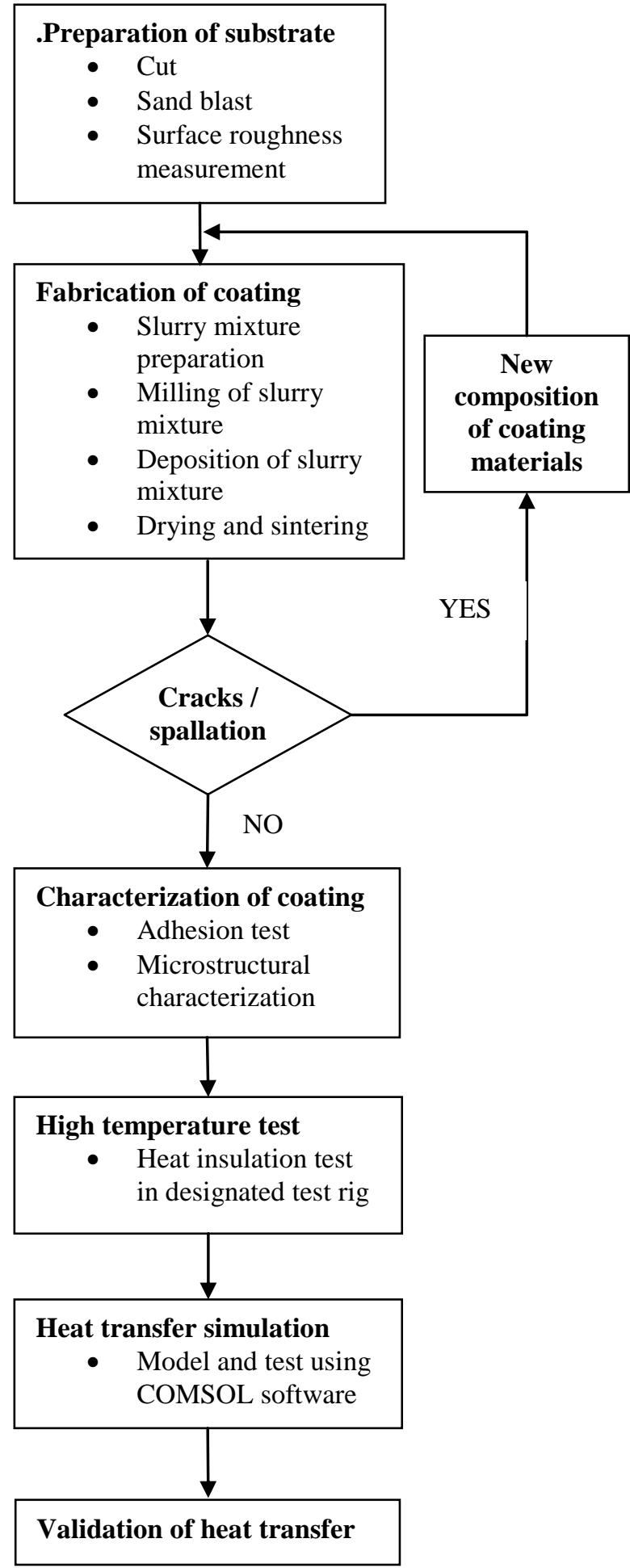

Figure 3 - Research Methodology Flowchart. 


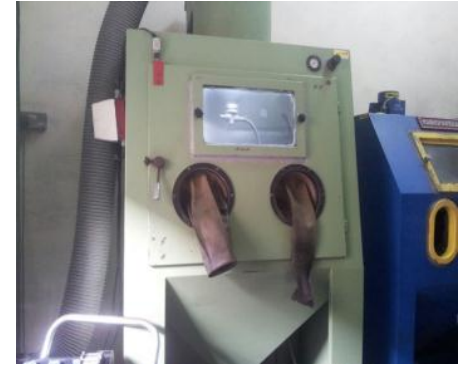

Figure 4: Image of the sand blasting machine.

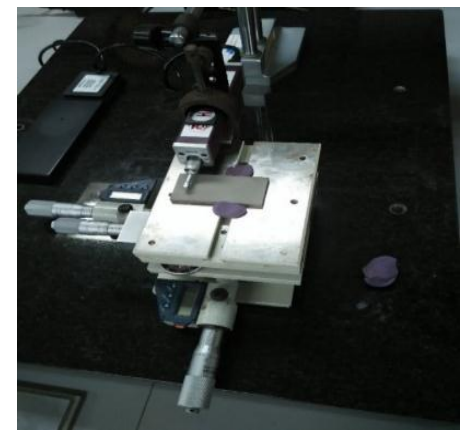

Figure 5 - Image of the instrument used for measuring substrate surface roughness.

\section{B. Preparation of Coating Mixture}

The coating mixture consist of solvent, raw materials, binder and dispersant. The raw materials are selected composition mixture of the ceramic, metal and chromium powder. The binder that will be used is polyvinyl alcohol (PVA) which can provide strength and adhesion to the coating and substrate (Buss et al., 2011; Chen et al., 2012). Besides, PVA will reduce the pore space in the coating thus, making the coating system more compact and strong. As for the dispersant, ammonium citrate tribasic will be used to enhance the diffusion and decrease the agglomeration of particles inside the coating mixture (Waldbillig and Kesler, 2009; Eroglu et al., 2013). On the other hand, distilled water will be used as the solvent as it will be easily and completely evaporated after coating deposition. After all the coating materials have been mixed in appropriate amount, the milling process will be conducted for 3 hours in the presence of zirconia balls. The balls will break apart any agglomerated particles and decrease the grain size of the powder (Michalska et al., 2014; Liu et al., 2015).

\section{Deposition of coating mixture}

Before the coating mixture is deposited, the substrate will be cleaned thoroughly with detergent and distilled water to remove the residual sand and contaminants. Then, it will be degreased in acetone and keep in ethanol to ensure that the substrate is contaminant-free (Yao et al., 2014; Di Girolamo et al., 2015; Imran et al., 2015). After milling process has finished, the coating mixture will be deposited onto the substrate. The coating will be applied by automatic film applicator. This machine uses motorized method of driving wire coating bars across the substrate at constant speed (Sheen, 2006). The coating bars control the thickness of the coating which ranges from 50 to $300 \mu \mathrm{m}$. This instrument speed range is from 50 to $500 \mathrm{mms}^{-1}$ with increment of 10 $\mathrm{mm}^{-1}$. Figure 6 shows the automatic film applicator. After selecting the suitable coating bar and setting the speed, the coating process will be started by controlling the forward and return button.

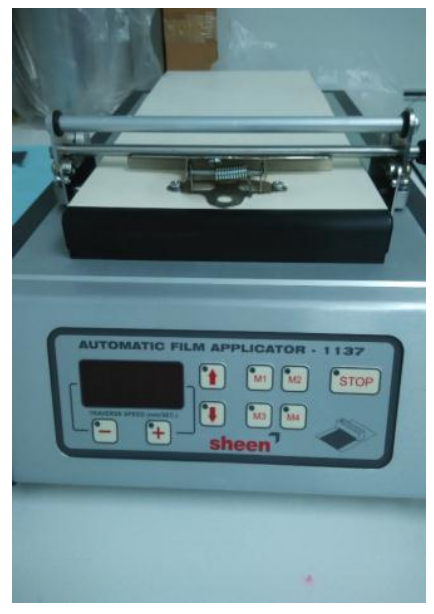

Figure 6 - Image of the automatic film applicator.

\section{vII. Results and Discussion}

The result comprises of determining the optimum conditions for Ni-Basalt fibre ceramic coating. The parameters tested are different sintering temperatures, different ceramic coating compositions, different surface roughness of substrates, different coating thickness and lastly, different condition inside the furnace during sintering process. From all the listed parameters, two parameters have been successfully tested while the other parameters are yet to be tested. Different sintering temperatures and different compositions already been tested and analyzed using VPSEM and EDX.

\section{vIII. Conclusion}

As a conclusion, a new compositional ceramic coating system has been introduced which involved the application of Basalt fibre ceramic to replace yttria stabilized zirconia. This new material is expected to reduce the heat transfer in the turbocharger turbine volute casing compared to yttria stabilized zirconia as it has many advantages compared to yttria stabilized zirconia. The materials selection has considered as many criteria as possible in order to produce a strong, high thermal and corrosion resistance coating system.

\section{Acknowledgment}

The authors would like to thanks the Faculty of Mechanical Engineering and Universiti Teknologi Malaysia 
(UTM) for providing the research facilities. This research work has been supported by the UTM Research University Grant (01G51) and the grant (4F445) from Ministry of Ministry of Education Malaysia (MOE).

\section{References}

[1] Ahmadi-pidani, R. et al., 2014. Improving the hot corrosion resistance of plasma sprayed ceria - yttria stabilized zirconia thermal barrier coatings by laser surface treatment. Journal of Materials\&Design, 57, pp.336-341. Available

http://dx.doi.org/10.1016/j.matdes.2013.12.075.

[2] Bocanegra-Bernal, M.H. \& Matovic, B., 2010. Mechanical properties of silicon nitride-based ceramics and its use in structural applications at high temperatures. Materials Science and Engineering: A, 527(6), pp.1314-1338. Available http://dx.doi.org/10.1016/j.msea.2009.09.064.

[3] Bontempo, R. et al., 2015. Steady and unsteady experimental analysis of a turbocharger for automotive applications. Energy Conversion and Management, 99, pp.72-80. Available at: http://www.sciencedirect.com/science/article/pii/S0196890415003799

[4] Buss, F. et al., 2011. Effect of soluble polymer binder on particle distribution in a drying particulate coating. Journal of Colloid and Interface Science, 359(1), pp.112-120.

[5] Chauhan, K. V. \& Rawal, S.K., 2014. A Review Paper on Tribological and Mechanical Properties of Ternary Nitride based Coatings. Procedia Technology, 14, pp.430-437. Available at: http://www.sciencedirect.com/science/article/pii/S2212017314000917

[6] Chen, G.Q. et al., 2012. Preparation and characterization of a sodium polyacrylate/sodium silicate binder used in oxidation resistant coating for titanium alloy at high temperature. Powder Technology, 230, pp.134-138.

[7] Chen, M. et al., 2013. Effect of sand blasting and glass matrix composite coating on oxidation resistance of a nickel-based superalloy at 1000 C. , 73, pp.331-341. Available at: http://ac.elscdn.com/S0010938X13001479/1-s2.0-S0010938X13001479main.pdf?_tid=f395c910-59f3-11e4-917b-

00000aab0f6c\&acdnat $=1413986682 \_$2bf87373f5293e8247510814de5 78925.

[8] Eriksson, R. et al., 2013. Surface \& Coatings Technology In fl uence of substrate material on the life of atmospheric plasma sprayed thermal barrier coatings. , 232, pp.795-803.

[9] Eroglu, D. et al., 2013. Use of dispersants to enhance incorporation rate of nano-particles into electrodeposited films. Electrochimica Acta, 113, pp.628-634.

[10] Galindo, J. et al., 2013. Characterization of a radial turbocharger turbine in pulsating flow by means of CFD and its application to engine modeling. Applied Energy, 103, pp.116-127. Available at: http://www.sciencedirect.com/science/article/pii/S0306261912006538 Inhttp://linkinghub.elsevier.com/retrieve/pii/S0306261912006538.

[11] Gao, L. et al., 2015. Microstructure and mechanical properties of yttria stabilized zirconia coatings prepared by plasma spray physical vapor deposition. Ceramics International, 41(7), pp.8305-8311. Available at: http://www.scopus.com/inward/record.url?eid=2-s2.084929276640\&partnerID=tZOtx3y1.

[12] Di Girolamo, G. et al., 2015. Microstructural, mechanical and thermal characteristics of zirconia-based thermal barrier coatings deposited by plasma spraying. Ceramics International, 41(9), pp.11776-11785. Available

http://linkinghub.elsevier.com/retrieve/pii/S0272884215010901.

[13] Gosai, D.C. \& Nagarsheth, H.J., 2014. Performance and Exhaust Emission Studies of an Adiabatic Engine with Optimum Cooling. Procedia Technology, 14, pp.413-421. Available at: http://linkinghub.elsevier.com/retrieve/pii/S2212017314000899.

[14] Heimann, R.B., 2010. Thermal spraying of silicon nitride coatings using highly accelerated precursor powder particles. Surface and Coatings Technology, 205(4), pp.943-948. Available at: http://dx.doi.org/10.1016/j.surfcoat.2010.02.049.

[15] Hejwowski, T., 2010. Comparative study of thermal barrier coatings for internal combustion engine. Vacuum, 85(5), pp.610-616. Available at: http://dx.doi.org/10.1016/j.vacuum.2010.08.020.
[16] Imran, A. et al., 2015. Micro structural study of plasma-sprayed zirconia-CaO thermal barrier coatings, Elsevier Ltd. Available at: http://dx.doi.org/10.1016/j.matpr.2015.11.043.

[17] Jalaludin, H.A. et al., 2013. Experimental study of ceramic coated piston crown for compressed natural gas direct injection engines. Procedia Engineering, 68, pp.505-511. Available at: http://dx.doi.org/10.1016/j.proeng.2013.12.213.

[18] Jin, X.Q. \& Zhao, C.Y., 2015. Numerical investigation on the effective thermal conductivity of plasma sprayed zirconia coatings.

[19] Josell, D. et al., 2015. Heat transfer through nanoscale multilayered thermal barrier coatings at elevated temperatures. Surface and Coatings Technology, 275, pp.75-83. Available at: http://www.sciencedirect.com/science/article/pii/S0257897215300220

[20] Keshavarz, M., Idris, M.H. \& Ahmad, N., 2013. Mechanical properties of stabilized zirconia nanocrystalline EB-PVD coating evaluated by micro and nano indentation. Journal of Advanced Ceramics, 2(4), pp.333-340. Available at: http://link.springer.com/10.1007/s40145-013-0080-y.

[21] Khan, A.A. et al., 2016. Effect of grit-blasting air pressure on adhesion strength of resin to titanium. International Journal of Adhesion and Adhesives, 65, pp.41-46.

[22] Kim, M.-S. et al., 2014. Thermal durability of thermal barrier coatings with layered bond coat in cyclic thermal exposure. Journal of the Ceramic Society of Japan, 122(1432), pp.982-988. Available at: https://www.jstage.jst.go.jp/article/jcersj2/122/1432/122_JCSJP14034/_pdf.

[23] Kumar, R.S., Sivakumar, D. \& Gandhi, A.S., 2012. Processing and properties of silicon carbide and its composites containing MoSi2 and ZrB2. Materials Science and Engineering: A, 540, pp.107-114. Available http://linkinghub.elsevier.com/retrieve/pii/S092150931200158X.

[24] Kumar, V. \& Balasubramanian, K., 2016. Progress update on failure mechanisms of advanced thermal barrier coatings: A review. Progress in Organic Coatings, 90, pp.54-82. Available at: http://linkinghub.elsevier.com/retrieve/pii/S0300944015301545.

[25] Laengler, F., Mao, T. \& Scholz, A., 2011. Investigation of application-specific phenomena to improve the lifetime assessment for turbine housings of turbochargers. Procedia Engineering, 10, pp.1163-1169. Available http://dx.doi.org/10.1016/j.proeng.2011.04.194.

[26] Lu Z, Xian G, Li H. Effects of exposure to elevated temperatures and subsequent immersion in water or alkaline solution on the mechanical properties of pultruded BFRP plates. Compos Part B Eng. 2015;77:421-430. doi:10.1016/j.compositesb.2015.03.066.

[27] Matovi, B., Yano, T. \& Outline, C., 2013. Silicon Carbide and Other Carbides: From Stars to the Advanced Ceramics. Handbook of Advanced Ceramics, pp.225-244.

[28] Michalska, M. et al., 2014. In fl uence of milling time in solid-state synthesis on structure, morphology and electrochemical properties of Li 4 Ti 5 O 12 of spinel structure. , 266, pp.372-377.

[29] Mukherjee, J. et al., 2014. Mechanical and tribological properties of silicon carbide coating on Inconel alloy from liquid pre-ceramic precursor. Ceramics International, 40(5), pp.6639-6645. Available at: http://www.sciencedirect.com/science/article/pii/S0272884213015769

[30] Myagkov, L.L. et al., 2014. 11 - Advanced and conventional internal combustion engine materials, Available at: http://www.sciencedirect.com/science/article/pii/B978085709522050 $011 \mathrm{X}$

[31] Nor, A.M., Abbas, M. \& Rajoo, S., 2014. Review on Ceramic Application in Automotive Turbocharged Engines. Applied Mechanics ..., 660, pp.219-228. Available at: http://www.scientific.net/AMM.660.219.

[32] Pakseresht, A.H. et al., 2016. Surface \& Coatings Technology Evaluation of hot corrosion behavior of plasma sprayed thermal barrier coatings with graded intermediate layer and double ceramic top layer. , 288, pp.36-45.

[33] Park, D.J. et al., 2014. Oxidation Behavior of Silicon Carbide at $1200^{\circ} \mathrm{C}$ in Both Air and Water-vapor-rich Environments. Corrosion Science, 88 , pp.416-422. Available at: http://www.sciencedirect.com/science/article/pii/S0010938X1400379 5.

[34] Romagnoli, A. \& Martinez-Botas, R., 2012. Heat transfer analysis in a turbocharger turbine: An experimental and computational evaluation. 
Applied Thermal Engineering, 38, pp.58-77. Available at: http://dx.doi.org/10.1016/j.applthermaleng.2011.12.022.

[35] Saidur, R. et al., 2012. Technologies to recover exhaust heat from internal combustion engines. Renewable and Sustainable Energy Reviews, 16(8), pp.5649-5659. Available at: http://www.sciencedirect.com/science/article/pii/S1364032112003474

[36] Sharma, D., 2015. a Review of Development in I . C . Engine Waste Heat Recovery Technologies Using a Review of Development in I . C . Engine Waste Heat Recovery Technologies Using., (October).

[37] Sheen Instruments Ltd. 2006. Automatic Film Applicator: Operating Manual. England: Sheen.

[38] Singha K. A Short Review on Basalt Fiber. Int J Text Sci. 2012;1(4):19-28. doi:10.5923/j.textile.20120104.02

[39] Sivakumar, G. \& Senthil Kumar, S., 2014. Investigation on effect of Yttria Stabilized Zirconia coated piston crown on performance and emission characteristics of a diesel engine. Alexandria Engineering Journal, 53(4), pp.787-794. Available at: http://dx.doi.org/10.1016/j.aej.2014.08.003.

[40] Sobhanverdi, R. \& Akbari, A., 2015. Porosity and microstructural features of plasma sprayed Yttria stabilized Zirconia thermal barrier coatings.

[41] Sommers, a. et al., 2010. Ceramics and ceramic matrix composites for heat exchangers in advanced thermal systems-A review. Applied Thermal Engineering, 30(11-12), pp.1277-1291. Available at: http://dx.doi.org/10.1016/j.applthermaleng.2010.02.018.

[42] Vannan SE, Vizhian SP, Karthigeyan R. Investigation on the Influence of Basalt Fiber on Thermal properties of A17075/ Basalt Fiber Metal Matrix Composites. Procedia Eng. 2014;97:432-438. doi:10.1016/j.proeng.2014.12.267

[43] Waldbillig, D. \& Kesler, O., 2009. The effect of solids and dispersant loadings on the suspension viscosities and deposition rates of suspension plasma sprayed YSZ coatings. Surface and Coatings Technology, 203(15), pp.2098-2101.

[44] Wu, S. et al., 2015. Oxidation protective silicon carbide coating for $\mathrm{C} / \mathrm{SiC}$ composite modified by a chromium silicide-chromium carbide outer layer. Materials Science and Engineering: A, 644, pp.268-274. Available http://linkinghub.elsevier.com/retrieve/pii/S0921509315302331.

[45] Xu, J. et al., 2015. Stability of interfaces in hybrid EBC/TBC coatings for Si-based ceramics in corrosive environments. International Journal of Refractory Metals and Hard Materials, 49, pp.339-349. Available at:

http://www.sciencedirect.com/science/article/pii/S0263436814002121

[46] Xu, Z. et al., 2014. Effect of grit blasting on the thermal cycling behavior of diffusion aluminide/YSZ TBCs. Journal of Alloys and Compounds, 586, pp.1-9.

[47] Yang, H. et al., 2012. Applied Surface Science Surface treatment of nickel substrate for the preparation of BSCCO film through sol - gel method. , 258, pp.4852-4856.

[48] Yang, M. et al., 2015. An investigation of volute cross-sectional shape on turbocharger turbine under pulsating conditions in internal combustion engine. Energy Conversion and Management, 105, pp.167-177. Available http://dx.doi.org/10.1016/j.enconman.2015.06.038

[49] Yao, J. et al., 2014. Thermal barrier coating bonded by (A12O3$\mathrm{Y} 2 \mathrm{O} 3) /(\mathrm{Y} 2 \mathrm{O} 3$-stabilized $\mathrm{ZrO} 2)$ laminated composite coating prepared by two-step cyclic spray pyrolysis. Corrosion Science, 80, pp.37-45. Available at: http://dx.doi.org/10.1016/j.corsci.2013.10.006.

[50] Zhang, J. et al., 2013. Gelcasting and pressureless sintering of silicon carbide ceramics using $\mathrm{Al} 2 \mathrm{O} 3-\mathrm{Y} 2 \mathrm{O} 3$ as the sintering additives. Journal of the European Ceramic Society, 33(10), pp.1695-1699. Available at: http://dx.doi.org/10.1016/j.jeurceramsoc.2013.02.009.

[51] Zhang, J. et al., 2015. Properties of silicon carbide ceramics from gelcasting and pressureless sintering. Materials \& Design, 65, pp.12$16 . \quad$ Available at: http://www.sciencedirect.com/science/article/pii/S0261306914006505

[52] Zhang, Y., Yuan, Z. \& Zhou, Y., 2014. Gelcasting of silicon carbide ceramics using phenolic resin and furfuryl alcohol as the gel former. Ceramics International, 40(6), pp.7873-7878. Available at: http://linkinghub.elsevier.com/retrieve/pii/S0272884213017501.

[53] Dhand V, Mittal G, Rhee KY, Hui D. A short review on basalt fiber reinforced polymer composites. Compos Part B Eng. 2014;73:166180. doi:10.1016/j.compositesb.2014.12.011.
[54] Fiore V, Scalici T, Di Bella G, Valenza A. A review on basalt fibre and its composites. Compos Part B Eng. 2015;74:74-94. doi:10.1016/j.compositesb.2014.12.034.

[55] Lipatov Y V., Arkhangelsky I V., Dunaev A V., Gutnikov SI, Manylov MS, Lazoryak BI. Crystallization of zirconia doped basalt fibers. Thermochim Acta. 2014;575:238-243. doi:10.1016/j.tca.2013.11.002.

About Authors:
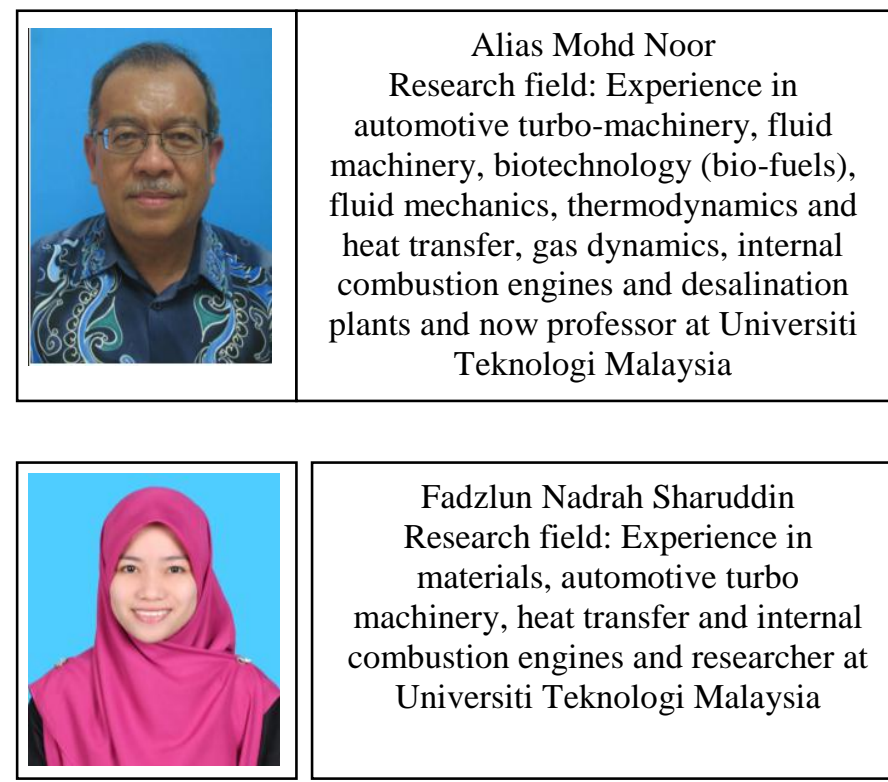

Fadzlun Nadrah Sharuddin Research field: Experience in materials, automotive turbo machinery, heat transfer and internal combustion engines and researcher at

Universiti Teknologi Malaysia

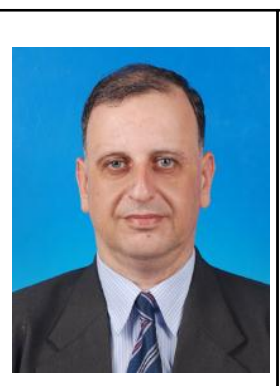

Uday M. Basheer

Research field: Experience in Advanced ceramic, Ceramic composite insulators, ceramic / metal joining, Friction welding, thermal barrier coating, Metal alloy, Materials characterizations and desalination plants and now Senior Lecturer at Universiti Teknologi Malaysia 